\title{
Grafting Science on Congress
}

\section{Lucia D. Simonelli}

As a theoretical mathematician interested in working on climate change initiatives, I was unsure how to navigate into the policy world. I owe the American Mathematical Society (AMS) a debt of gratitude for sponsoring the Congressional Fellowship, which served as an invaluable bridge between academia and public sector engagement.

As the AMS Congressional Fellow, I had the great honor to work for Senator Sheldon Whitehouse (RI) - a staunch advocate for science-on his mighty energy and environment team from October 2019 to August 2020. In addition to learning about the legislative process, I had the opportunity to understand the value of fellowship programs such as this one, to reflect on how mathematical training can fit into a broader context, and to experience how scientists contribute to policy.

Over the course of my fellowship year, I learned about a very concerning shift in structure and quantity of Congressional staff over recent decades. With this context as backdrop, I understood more profoundly the importance of fellowships like this one.

In the past, there were actually more Congressional staff. There were also substantially more staff serving in the Congressional support agencies; these support agencies are essential to the health and function of the legislative branch as they provide neutral, confidential, and credible resources to members and staff. Congress even had its own "think tank" called the Office of Technology Assessment (OTA) with a mission and capacity to anticipate the scientific, technological, and medical issues that would eventually necessitate policy action.

In the mid 1990s, under the guise of an initiative called "Contract with America," Congress was stripped of many of these vital resources. Staff was cut significantly, and the

Lucia D. Simonelli is the 2019-2020 AMS Congressional Fellow.

More information on the AMS Congressional Fellowship can be found here: https://www.ams.org/ams-congressiona1-fe11owship. The 2021 Congressional Fellowship application deadline is February 1, 2021.

For permission to reprint this article, please contact: reprint-permission aams.org.

DOI: https://dx.doi.org/10.1090/noti2210
OTA was entirely defunded-targeting the OTA specifically was a political gesture. As the smallest legislative branch agency, it was the easiest to eliminate. And, it was a very powerful symbol to cite the elimination of an entire agency, especially to bolster a platform founded on budget cuts. To provide a bit of context, the budget of the OTA was less than $1 \%$ of the legislative branch budget.

Despite it being relatively small, however, there was something very special about the OTA. The OTA has been described as Congress's "trusted intermediary, taking information, restricting it to fact-based arguments, and presenting it accordingly." The staff at OTA, many of whom were scientists, medical professionals, and experts in other technical fields, and the network of experts created through the production of comprehensive reports, served as invaluable, nonpartisan, consultative resources to Congress. The OTA staff was often integrated directly with Congressional staff, and they were available to serve as in-house experts.

One of the primary functions of the OTA was to craft "horizon scanning" reports which included the most cutting-edge findings available, compiled in a form utilizable by Congress. While not ever making policy recommendations, these reports provided comprehensive analyses of the policy options and the implications of these options through a transparent process. These reports laid the foundation for many key pieces of legislation and remain highly regarded among experts in various technical fields. Princeton University has preserved an archive of these reports: https://www. princeton. edu/ ota/.

Defunding the OTA and cutting staff and capacities of other agencies has serious implications, especially as we face an increasing number of issues that require technical expertise-pandemics, climate change, cybersecurity and quantum computing, etc. Congress increasingly relies on outside stakeholders for expert advice and information. While stakeholders' perspectives are invaluable, special interest and bias inevitably accompany these sources. Congress also now heavily relies on executive branch agencies-the very agencies for which Congress is tasked to provide oversight. 
Fortunately, there are various efforts to increase inhouse science and technology resources for Congress. One such effort is the Science \& Technology Policy Fellowship program organized by the American Association for the Advancement of Science (AAAS). This program places $\mathrm{PhD}$ scientists across all branches of government for one or two years; about 30 of these fellows work in Congress. Funding for these Congressional fellows comes predominately from external sources, such as science societies like the AMS.

Congressional fellows are in high demand-last year around 90 Congressional offices/committees actively requested to have a fellow. After the fellowship year, many fellows stay in government positions, some return to academia, others join NGOs or think tanks. Over the years, a powerful network of scientists with experience in policy has been created.

Looking back to the beginning of the fellowship year, I remember that it was not immediate how to articulate which aspects of my training in theoretical mathematics would transfer to useful skills in the policy world-especially since I was interested in working on climate change initiatives, an issue far removed from my academic background. But throughout the year I was able to truly appreciate that a scientific training provides important and universally transferrable skills beyond just the more commonly recognized quantitative and analytic abilities.

Through observing the work of my mentors, I realized that even in policymaking, creativity can separate the average from the exceptional. Before spending a year in the Senate, I viewed the law-making process as mechanical and formulaic-similarly to how math can be perceived from the outside. One characteristic of a successful legislator is the ability to creatively craft and formulate policy in order to capitalize on unconventional opportunities and unexpected legislative vehicles. The rigor and creativity of scientific training combined with an understanding of the legislative process enables fellows to be well-positioned to grow into powerful policymakers.

A training in science, and especially mathematics, provides the gift of humility to distinguish between profound understanding and superficial familiarity-I have learned when I really know something and, of equal importance, when I don't. I have become increasingly comfortable with not knowing, even when thrown into an unfamiliar world, because a mathematical training equipped me with the capacity to navigate how and when to learn what I don't know. I have not always fully appreciated this versatility, but it proved invaluable for the high-paced and demanding work of Congress.

Studying mathematics also demonstrates the importance of learning and using the appropriate "language" for a given context. Language can change even between fields, but beautiful results and novel ideas are born from learning and combining different languages. After being trained for many years to use a very technical type of language, it was an extremely difficult but important exercise to understand how to successfully convey concepts in varying contexts to diverse audiences. In Congress, language is based on procedure, politics, protocol, and precedent. To be effective legislatively, one must learn these axioms, and they are near to impossible to comprehend independently or externally; guidance and immersion are necessary. A fundamental component of the fellowship experience is learning how to effectively communicate in a new setting, and I am extremely grateful to Senator Whitehouse and his staff for the time, energy, and patience they devoted to teaching me their language.

In short, my experience as a Congressional fellow felt much like a graft-I was a mathematician coming from academia, inserted into the United States Senate. This opportunity exists because of entities like the AMS, it is nurtured through the guidance and support of Congressional members and staff, and it is sustained by the expertise, skills, and adaptability of scientists. While science and policy often live in two very different worlds, truly special things can grow when they coexist.

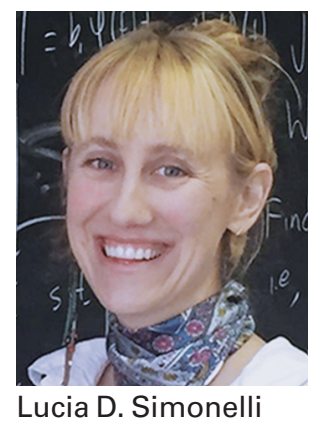

Credits

Author photo is courtesy of the author. 